OSAHS

\title{
Olfactory evaluation in obstructive sleep apnoea patients
}

\author{
Valutazione olfattiva di pazienti affetti da sindrome delle apnee ostruttive \\ del sonno

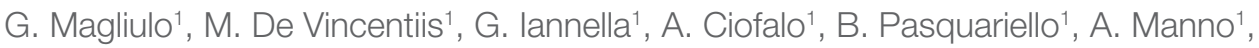 \\ D. Angeletti ${ }^{1}$, A. Polimeni \\ ${ }^{1}$ Department of Organi di Senso; ${ }^{2}$ Department of Oral and Maxillo Facial Sciences, University Sapienza, Rome, \\ Italy
}

\section{SUMMARY}

The sense of smell has a high impact on the quality of life. The aim of the present study was to investigate olfactory dysfunction in patients with obstructive sleep apnoea syndrome (OSAS) and correlate the severity of disease with olfactory dysfunction. The relationships between nasal obstruction, nasal mucociliary cleareance and olfactory tests were also evaluated. Sixty patients with a diagnosis of OSAS were enrolled and underwent olfactory function evaluation. In all patients olfactory performance was tested with the Sniffin' Sticks method. Mucociliary transport times and anterior rhinomanometry were performed to identify eventual nasal obstruction and deficits in nasal mucociliary clearance. Olfactory dysfunction was present in 22 (36.6\%) patients of the study group: of these, hyposmia was present in 19 (86.4\%) and anosmia in $3(13.6 \%)$. The mean TDI score in the study group was 30. A strong correlation between the olfactory dysfunction and severity of sleep apnoea measured using the AHI was found. Patients with OSA would seem to have a high incidence of olfactory dysfunction. The degree of olfactory dysfunction appears to be related to the severity of disease. However, other co-factors such as nasal obstruction and reduced mucociliary clearance might also play a role in of the aetiology of this condition.

KEY WORDS: Obstructive sleep apnoea syndrome $\bullet$ Olfactory dysfunction • Sniffin’ Sticks • Nasal mucociliary clearance • Anterior rhinomanometry

\section{RIASSUNTO}

Il senso dell'olfatto ha un alto impatto sulla qualità della vita. Lo scopo di questo studio è stato quello di investigare la disfunzione olfattiva in pazienti con sindrome delle apnee ostruttive del sonno (OSA) e correlare la gravità della malattia con la perdita di olfatto. Inoltre, è stata valutata la relazione esistente tra ostruzione nasale, cleareance mucociliare nasale e i risultati dei test olfattivi. Sessanta pazienti con diagnosi di OSA sono stati arruolati in questo studio e hanno eseguito una valutazione olfattiva. In tutti i pazienti la valutazione olfattiva è stata eseguita attraverso lo Sniffin' Sticks test. Il tempo di trasporto mucociliare e una rinomanometria anteriore sono stati eseguiti per identificare una possibile ostruzione nasale e un deficit nella cleareance mucociliare. Una disfunzione olfattiva era presente in 22 (36,6\%) pazienti dello studio. In questi pazienti con disfunzione olfattiva l'iposmia era presente in 19 (86,4\%) casi e l'anosmia in 3 (13,6\%) casi. Il TDI medio del gruppo di studio presentava uno score di 30. Si è riscontrata una correlazione statistica tra la disfunzione olfattiva e la severità delle apnee notture misurata con AHI. I pazienti con OSA sembrerebbero avere un'alta incidenza di disfunzione olfattiva. Il grado di disfunzione olfattiva sembrerebbe essere correlato alla gravità della malattia. Tuttavia, altri fattori come una ostruzione nasale e una ridotta cleareance mucociliare sembrerebbero avere un ruolo nell'eziologia di questa condizione.

PAROLE CHIAVE: Sindrome delle apnee ostruttive del sonno $\bullet$ Disfunzione olfattiva $\bullet$ Sniffin’ Sticks $\bullet$ Cleareance mucociliare nasale $\bullet$ Rinomanometria anteriore

Acta Otorhinolaryngol Ital 2018;38:338-345

\section{Introduction}

Obstructive sleep apnoea syndrome (OSAS) is a condition characterised by pauses in breathing and episodes of reduction (hypopnea) or absence (apnea) of airflow in the upper airways during sleep ${ }^{1-4}$. OSAS is becoming more commonly recognised because of its significant negative effects on daily life and its association with neurocognitive and psychological problems, such as memory and new learning, attention, executive function and depres- 
sion ${ }^{156}$. According to the study published by Heinzer et al. ${ }^{7}$ the incidence of moderate-to-severe sleep-disordered breathing ( $\geq 15$ events per hour) is $23.4 \%$ in women and $49.7 \%$ in men.

The sense of smell is a sensorineural system with a high impact on the quality of life ${ }^{8-10}$. Data regarding the incidence of olfactory dysfunctions in the healthy population vary between $10 \%$ and $46 \%$ of the healthy population ${ }^{10-15}$. A recent study of a large population showed that the overall incidence of olfactory dysfunction was $19.1 \%$, consisting of $13.3 \%$ and $5.8 \%$ of patients with hyposmia and anosmia, respectively ${ }^{16}$. Similar data were reported by Hummel et al. ${ }^{11}$ with a $20 \%$ incidence of olfactory dysfunction in subjects between 36 and 55 years of age.

Sinonasal diseases, nasal obstruction, head trauma and central nervous system disorders that affect neurocognitive functions, drugs, and toxins are the most important causes of olfactory dysfunction (OD) ${ }^{10} 151819$. The conditions listed above may be variously present in OSAS patients, making these subjects more inclined to developing an olfactory dysfunction ${ }^{1-4} 20-22$.

To our knowledge, only a few authors have evaluated olfactory dysfunction in OSAS patients ${ }^{23-25}$ and there is a scarcity of data concerning the relationship between clinical findings and OD in the medical literature.

The aim of the present study was to investigate: 1) incidence of olfactory dysfunction in OSAS patients; 2) correlation between the severity of OSAS and OD; 3) relationships between nasal obstruction, nasal mucociliary clearance and olfactory test results in patients with OSAS.

\section{Materials and methods}

This prospective study was performed at the of Organi di Senso Department (Sleep Disorders Unit) of Sapienza University in Rome between January 2016 and February 2017.

The participants were selected from patients who were referred to us with a clinical suspicion of sleep apnoea syndrome. Initially, clinical data, including height and weight, in order to calculate body mass index (BMI), medical history, tobacco use and a list of current medications were collected for each patient.

Subsequently, each patient was submitted to an ENT physical examination with nasal endoscopy $\left(2.7 \mathrm{~mm} 0^{\circ}\right.$ rigid endoscope) to evaluate the features of nasal structures and detect any rhino-sinusal pathologies.

The exclusion criteria for this study included patients with a history of upper respiratory infections within the previous 3 weeks, sinonasal disorders (nasal polyps, chronic rhinosinusitis, allergic rhinitis), asthma, malignancy, head trauma, neurological and psychiatric disorders, metabolic and endocrine disorders, or a recent history of smoking more than 3 cigarettes per day.

Patients who underwent sleep surgery or currently using continuous positive airway pressure were not included in the study.

All patients selected for the study had previously undergone a polysomnographic (PSG) study to confirm diagnosis of OSAS and assess its severity.

All parameters, sleep stage scoring and event scoring were evaluated in accordance with the AASM Manual for the Scoring of Sleep and Associated Events ${ }^{26}$.

Diagnosis of OSAS was confirmed when the number of obstructive events (apnoeas, hypopneas + respiratory event related arousals) on PSG were $>15$ events/hour or $>5 /$ hour in patients reporting typical symptomatology (unintentional sleep episodes during wakefulness; daytime sleepiness; unrefreshing sleep; fatigue; insomnia; waking up holding breath, gasping or choking; or loud snoring, breathing interruptions or both during the patient's sleep as described by the bed partner) ${ }^{2627}$.

In accordance with American Academy of Sleep Medicine (AASM) guidelines, OSAS severity was classified on the basis of the apnoea + hypopnoea index (AHI). The grade of OSAS was classified as normal $(\mathrm{AHI}<5 / \mathrm{h})$, mild (AHI $\geq 5$ and $<15$ plus typical symptomatology), moderate $\left(\mathrm{AHI} \geq 15\right.$ and $<30$ ) or severe $(\mathrm{AHI} \geq 30)^{2627}$.

Once the exclusion criteria was applied, 60 patients with a PSG diagnosis of OSAS were enrolled in the study. During enrollment of these patients, 20 subjects were selected from each OSA category (mild, moderate, severe) to form three homogeneous groups for better comparison of olfactory results.

The same exclusion criteria adopted for the study group were applied for selection of a control group of patients without OSAS. In all the patients of the control group the typical symptomatology of OSAS patients was excluded and the results of PSG examination showed AHI $<5$. Forty volunteer subjects were enrolled in this control group. All OSAS patients enrolled in the study group underwent evaluation of olfactory function. Anterior rhinomanometry and mucociliary transport time were performed to evaluate nasal obstruction and mucociliary clearance. The same study protocol was adopted for the control group.

The study was performed in accordance with the principles of the Declaration of Helsinki and approved by the local Ethics Committee of the University Sapienza of Rome.

All patients gave written informed consent for the PSG, olfactory test, rhinomanometry and saccharin test. 


\section{Evaluation of olfactory function}

Olfactory performance was tested with the Sniffin' Sticks (Burghart, Wedel, Germany) method ${ }^{28-30}$. This test includes 3 sub-tests that evaluate the olfactory threshold (OD), olfactory discrimination (ODs) and identification (OI). The sum of the results from each of three different sub-tests results in a total score defined as TDI. In the analysis of Sniffin' Sticks tests, the results of the TDI score indicated hyposmia when the total TDI score was $<30.5$, anosmia when $<16.5$ and no OD when the TDI score was $>30.5^{28-30}$.

\section{Rhinomanometry}

Nasal resistance was evaluated in both OSAS patients and in the control group using anterior rhinomanometry. It has been reported in the literature that the mean total resistance in normal subjects ranges between 0.15 and $0.3 \mathrm{~Pa} / \mathrm{cm}^{3} / \mathrm{s}^{31}$. For this reason, total nasal airway resistance $>0.3 \mathrm{~Pa} / \mathrm{cm}^{3} / \mathrm{s}$ was considered pathological.

\section{Mucociliary transport time}

Mucociliary transport times were evaluated to identify possible deficits of nasal mucociliary clearance. Mucociliary transport time was evaluated in each patient using the saccharin test, which is a very simple, quick, non-invasive and reproducible method ${ }^{32}{ }^{33}$. About $2.5 \mathrm{mg}$ of granulated saccharin was placed $1 \mathrm{~cm}$ posterior and inferior to the head of the inferior turbinate with patients placed in the sitting position with the head bent forward. Patients were instructed to swallow every 30 seconds and not to sniff, sneeze or wipe their noses until they tasted the saccharin. The time from placement to perception of sweet taste was recorded as the nasal mucociliary clearance time (NMCT) ${ }^{32}{ }^{33}$. The same test was performed in OSAS patients and the study group.

\section{Statistical analysis}

For comparison of data between groups, the chi-square, Student's T test and regression analysis were performed using XLSTAT software (Addinsoft, 2015). A p value $<0.05$ was considered as statistically significant.

\section{Results}

The characteristics of the 60 patients of the study group are summarised in Table I.

Regarding the 60 patients of the study group, 38 were male and 22 were female, with an average age of 53.1 years (range 32-77). The average age of the three subgroups was 51.8, 54.5 and 53.4 in the mild, moderate and severe OSA subgroups respectively. The average age of the control group was 48.4 years. No difference emerged regarding mean patient age between the study and control groups $(p=0.1)$. Moreover, no differences were seen in mean age between the OSA subgroups ( $p>0.05$ for all).

\section{Olfactory evaluation}

Olfactory dysfunction was present in $22(36.6 \%)$ patients of the study group. Of these, hyposmia was present in $19(86.4 \%)$ cases and anosmia in $3(13.6 \%)$ cases. In the control group, 7 (17.5\%) patients showed olfactory dysfunction. There was a statistically difference between the study and control groups $(\mathrm{p}=0.04)$.

The mean TDI score of the study group was 30 (S.D. $=8.09 ; \mathrm{Hi}=39.0$; Low $=12.0$ ), whereas the mean TDI score in the control group was 33.3 (S.D. = 5.31; $\mathrm{Hi}=39.0$; Low $=14.0$ ) with a significant difference between groups $(\mathrm{p}=0.03)$.

Regarding olfactory data, it was interesting to note that $50 \%$ of patients with a diagnosis of olfactory dysfunction has severe OSAS. In addition, all 3 patients with a diagnosis of anosmia belonged to this subgroup.

Table I. Clinical characteristics of the study group.

$\begin{array}{lcc} & \text { OSAS group } & \text { Control group } \\ \mathbf{N}=\mathbf{4 0}\end{array}$




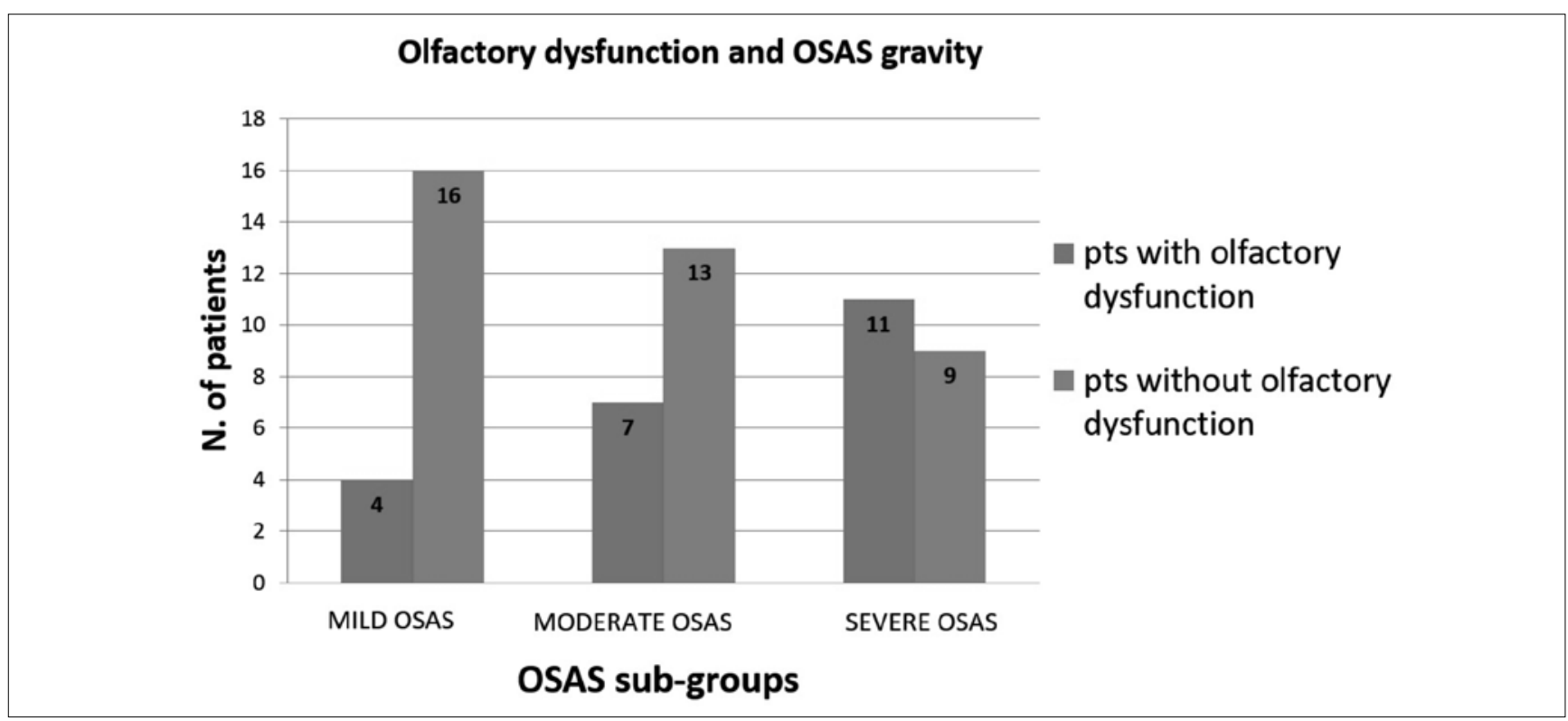

Fig. 1. Distribution of patients with olfactory dysfunction according to the OSAS subgroups.

The data regarding the distribution of olfactory dysfunction according to OSAS severity is summarised in Figure 1. A significant difference $(p=0.04)$ in olfactory dysfunction emerged only between mild and severe OSAS patients.

A strong correlation (regression analysis; $\mathrm{p}=0.04$; $\mathrm{R} 2=0.05$ ) between the olfactory dysfunction (TDI) and the severity of sleep apnoea using the AHI was found (Fig. 2).

Regression analysis between BMI and TDI did not show any correlation between high BMI and lower TMC scores $(p=0.07 ; R 2=0.06)$. Moreover, no correlation was present between TDI score and middle age $(\mathrm{p}=0.7$; $\mathrm{R} 2=0.002$ ).

\section{Rhinomanometry}

Thirty-seven patients (61.6\%) presented pathological bilateral values of nasal airway resistance atrhinomanometric examination. No differences regarding rhinomanometry results emerged for the different subclasses of OSAS patients. Nine patients $(22.5 \%)$ showed pathological values in the control group.

The difference in the incidence of pathological rhinomanometry between the study and control group was significant $(\mathrm{p}=0.0002)$.

\section{Mucociliary transport time}

The mean value of NMCT in OSAS patients was $13.2 \mathrm{~min}$ (S.D. $=3.13 ; \mathrm{Hi}=20.0 ;$ Low $=7.00 ;$ Median = 14.0). On the other hand, in the control group a lower NMCT mean

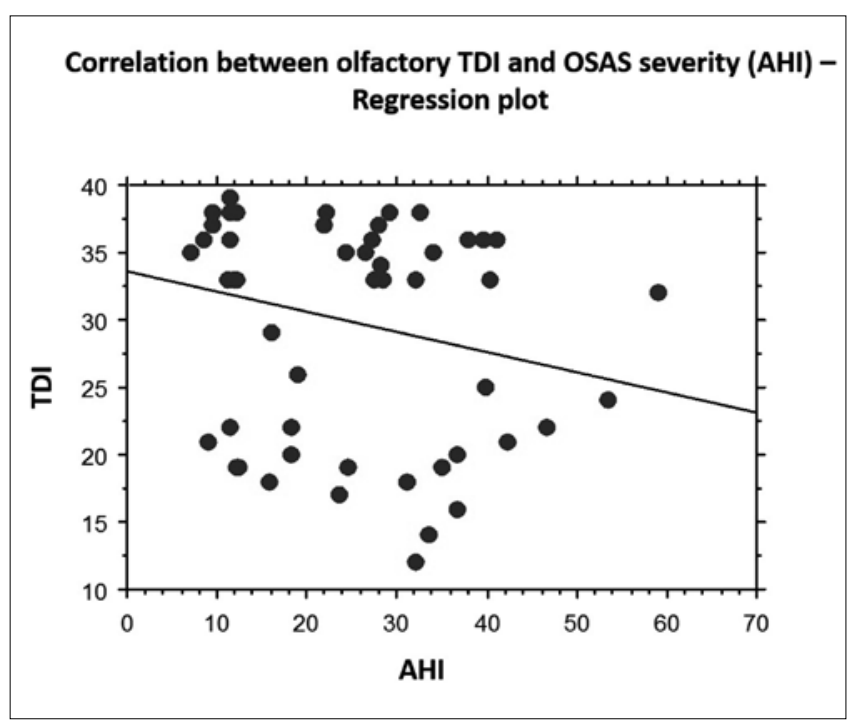

Fig. 2. Linear regression between olfactory TDI and OSAS severity (AHI): TDI had a significant and strong correlation with $\mathrm{AHI}(\mathrm{p}=0.001)$.

value $(\mathrm{Hi}=15 \mathrm{~min}$; Low $=5 \mathrm{~min})$ of $9.8 \mathrm{~min}$ was found. The difference between the two groups was statistically significant $(p=0.0001)$.

\section{TDI score, rhinomanometry and mucociliary transport time}

Comparing the results regarding nasal obstruction and olfactory evaluation (Table II): $86.3 \%$ of OSAS patients with olfactory dysfunction presented a pathological rhi- 
Table II. TDI score, rhinomanometry and mucociliary transport time of the study group divided according to the presence or absence of an olfactory dysfunction.

\begin{tabular}{|c|c|c|c|c|c|c|c|}
\hline & $\begin{array}{l}\text { Middle } \\
\text { age }\end{array}$ & P-value & $\begin{array}{l}\text { Pathological } \\
\text { rhinomanometry }\end{array}$ & $\begin{array}{c}\text { Normal } \\
\text { rhinomanometry }\end{array}$ & P-value & $\begin{array}{l}\text { Mucociliary transport } \\
\text { time (min) }\end{array}$ & P-value \\
\hline $\begin{array}{l}\text { OSAS with olfactory } \\
\text { dysfunction } \\
(\mathrm{N}=22)\end{array}$ & $\begin{array}{l}52.8 \\
\text { years }\end{array}$ & $p=0.9$ & $19(86.3 \%)$ & 3 (13.7\%) & $p=0.003$ & 14.7 & $p=0.005$ \\
\hline $\begin{array}{l}\text { OSAS without } \\
\text { olfactory } \\
\text { dysfunction } \\
(\mathrm{N}=38)\end{array}$ & $\begin{array}{l}53.2 \\
\text { years }\end{array}$ & & 18 (47.3\%) & 20 (52.7\%) & & 12.4 & \\
\hline
\end{tabular}

nomanometry outcome. There was a significant difference between patients with and without olfactory dysfunction in terms of rhinomanometry results $(p=0.003)$ This data might indicate that nasal obstruction is correlated to OSAS in patients with OD.

The average mucociliary transport time in patients with OD was greater than the mean value of OSAS patients without OD (14.7 min vs $12.4 \mathrm{~min}$ ). A significant difference between these two groups was seen $(p=0.005)$. Moreover, regression analysis between the TDI score and NMTC showed a significant correlation $(p=0.008)$ between increase of the NMTC and lower values of the TDI score (Fig. 3).

\section{Discussion}

The available data regarding the incidence and characteristics of olfactory dysfunctions in OSA patients are

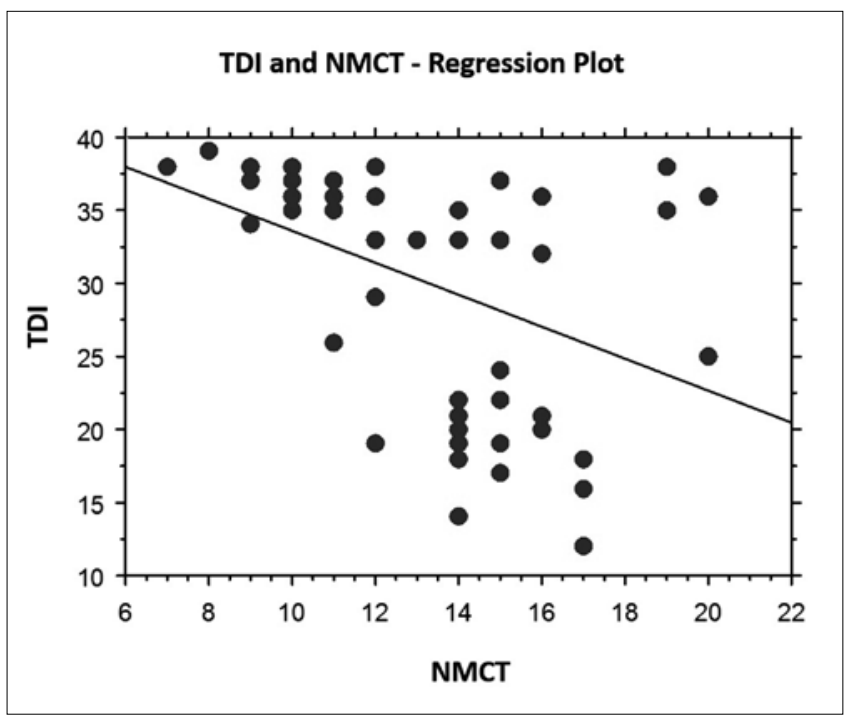

Fig. 3. Linear regression between olfactory TDI and nasal mucociliary clearance time: TDI had a significant and strong correlation with nasal mucociliary clearance time $(p=0.008)$. scarce ${ }^{23-25}$. Salihoglu et al. ${ }^{23}$ in a clinical study regarding the effects of obstructive sleep apnoea on olfactory functions demonstrated that OSAS has significant negative effects on olfactory capacity, especially on threshold values and discrimination. Recently, Günbey et al. ${ }^{24}$ in another clinical study regarding olfactory function in OSA patients, confirmed that patients with severe OSAS had scarce total odour scores with respect to non-snorers.

In accordance with these previous studies, we found that olfactory function declined in patients with OSAS. Olfactory dysfunction was present in 22 (36.6\%) patients in our clinical study. Hyposmia and anosmia were present in $86.4 \%$ and $13.6 \%$ of OSAS patients with OD respectively, indicating that hyposmia is the most common olfactory disorder affecting these patients.

The mean TDI score of the study group was 30 with a statistically significant difference between OSAS patients and the control group. In addition, our data regarding total TDI scores and their values in OSAS subclasses (Table II) appeared similar to those reported by Salihoglu et al. ${ }^{23}$ with mean values of $33.4 \pm 1.4$ in mild and moderate OSAS and $31.6 \pm 0.9$ in severe OSAS.

In our study, $50 \%$ of patients with a diagnosis of olfactory dysfunction had severe OSAS. A strong negative correlation emerged between the olfactory TDI score and the severity of the OSAS measured according to the apnoeahypopnoea index (AHI). A negative correlation between the olfactory parameters and the severity of sleep apnoea was also found in the study by Salihoglu et al. ${ }^{23}$.

Regarding BMI values and olfactory function in the study by Günbey et al. ${ }^{24}$, no significant differences emerged in terms of odour parameters, when the subjects were evaluated as obese $\left(\mathrm{BMI} \geq 28 \mathrm{~kg} / \mathrm{m}^{2}\right)$ and non-obese $\left(\mathrm{BMI}<28 \mathrm{~kg} / \mathrm{m}^{2}\right)$. Furthermore, Salihoglu et al. ${ }^{23} \mathrm{did}$ not observe any significant effect of BMI on the sum score of the Sniffin' Sticks subtests. The data observed in our study would seem to confirm this aspect.

Olfactory functions are generally negatively associated with age and tend to deteriorate further in the elderly ${ }^{33-35}$. 
Table III. OSAS group vs control group: olfactory evaluation, rhinomanometry and mucociliary transport time.

\begin{tabular}{lccc} 
& OSAS group & Control group & $\mathbf{N}=\mathbf{4 0}$ \\
& $\mathbf{N}=\mathbf{6 0}$ & $7(17.5 \%)$ & $\mathbf{P}$-value \\
Olfactory dysfunction: & $22(36.6 \%)$ & $6(85.7 \%)$ \\
Hyposmia & $19(86.4 \%)$ & $1(14.3 \%)$ \\
Anosmia & $3(13.6 \%)$ & \\
TDI score (mean value) & 30 & 33.3 \\
Mild OSAS & 33 & \\
Moderate OSAS & 30.7 & 9.04 \\
Severe OSAS & 26.2 & $9(22.5 \%)$ \\
Rhinomanometric examination & $3761.6 \%)$ & $9.8 \mathrm{~min}$ \\
NMCT (mean value) & $13.2 \mathrm{~min}$ & 0.03 \\
\hline
\end{tabular}

In our study, OSAS patients with OD did not have a higher mean age than those without OD (Table III). Regression analysis between TDI score and middle age did not identify any significant correlation $(p=0.7)$. This aspect would seem exclude age as a factor influencing olfactory results in OSAS patients. Moreover, no significant difference in mean age between the study group and control group was observed.

The olfactory epithelium is the first odour identification site. Odourants carried by the air enter into the nasal cavity and usually reach the olfactory mucosa through airflow. Subsequently, odourants dissolve within the surface of the olfactory mucosa and then bind to olfactory receptors in the surface of olfactory mucosa, producing nerve impulses ${ }^{10} 19$. In our opinion, especially in OSA patients, two important aspects related to the transport of odourants at the olfactory epithelium, should be analysed and discussed. These are possible nasal obstruction and nasal mucociliary clearance.

Patients with OSA most often present concurrent nasal obstruction ${ }^{21}{ }^{22}$. The latter has been implicated as an independent, aetiological factor in the pathogenesis of OSA, although no definite conclusions on the role of nasal obstruction in OSA pathogenesis have been reported ${ }^{21} 22$. It would seem that nasal obstruction results in an increase in upstream airflow resistance, which makes the pharynx vulnerable to collapse. During sleep, breathing is primarily nasal, but patients with nasal airway obstructions favour oral breathing, which decreases the hypopharyngeal space, leading to increased upper airway resistance and more frequent apnoeic and hypopnoeic episodes ${ }^{36-39}$.

Clearly, nasal obstruction is frequently associated with OD because it results in a reduction of the number of odourants that enter the nose during breathing ${ }^{1738}$. Only Fu et al. ${ }^{25}$ reported a relationship between nasal structure and olfactory function in patients with obstructive sleep apnoea. They investigated OSAS patients using acoustic rhinometry and found a correlation between nasal ob- struction and lower TDI score. Based on these data they suggested that nasal structure affects parameters of olfactory function, probably via alterations in nasal airflow.

In our study, we preferred to measure nasal air-flow directly via an anterior rhinomanometry. The OSAS patients in our study showed pathological bilateral values of nasal airway resistance in $61.6 \%$ of cases. Moreover, $86.3 \%$ of OSAS patients with olfactory dysfunction presented pathological rhinomanometry values. In our study, there was a significant difference between patients with and without olfactory dysfunction regarding rhinomanometry results, indicating that nasal obstruction could be a cofactor that is responsible for OD in these patients (Table III).

Inflammation of the nasal mucosa with alterations in nasal mucociliary clearance are a frequent cause of olfactory neuroepithelium dysfunction. Usually, poor mucociliary clearance hinders the interaction between odourous molecules contained in inspired air and the olfactory epithelium ${ }^{1637-40}$. Most OSAS patients present a reduced mucosal clearance even in the absence of evident sinonasal inflammatory diseases ${ }^{39-43}$. In a recent clinical study regarding nasal mucociliary clearance in obstructive sleep apneoa syndrome patients, Deniz et al. ${ }^{44}$ demonstrated that the nasal mucociliary system presents significant deterioration in severe OSAS patients.

The mean value of NMCT in the OSAS patients of our study was $13.2 \mathrm{~min}$ with a significant difference vs to the control group.

It is interesting to note that the mean mucociliary transport time in OSAS patients with OD was greater than the mean NMCT value of the OSAS patients without OD (14.7 min vs $12.4 \mathrm{~min}$ ). A statistically significant difference between these two groups emerged. Furthermore, regression analysis between TDI score and NMTC showed a significant correlation between the increase of the NMTC and lower values of the TDI score (Fig. 3). These findings could indicate that reduced mucociliary clearance represents another cofactor in the OD aetiology of OSAS patients. 
Gastro-oesophageal reflux disease (GERD) or laryngopharyngeal reflux disease (LPRD) may be comorbidities in patients with OSAS and an alteration of taste, due to acid aggression, might be possible in these patients ${ }^{45-48}$. However, such conditions do not seem to alter the results of mucociliary transport time measured using the saccharin test, because as reported by Altundag et al., no impairment in sweet taste is present in OSAS patients with LPRD ${ }^{4748}$. To avoid reflux and other possible subjective interferences, a composition of vegetable charcoal powder and saccharin powder at $3 \%$ could be used in alternative to the traditional saccharin test ${ }^{49}$.

Finally, regarding the aetiopathogenetic factors of OD in OSAS patients, it should be remembered that intermittent nocturnal hypoxia/reoxygenation episodes represent a trigger for upper airway inflammation and the increase of pro-inflammatory markers such as interleukin-8, tumour necrosis factor- $\alpha$, or C-reactive protein 405051 . It is possible that these inflammatory mediators might contribute to the harmful effects on olfactory neuroepithelium that occur in these patients. An extensive study through evaluation of inflammatory mediators (e.g. cytokines, interleukins, chemokines, TNF etc.) and nasal cytological aspects is under way in order to broaden current knowledge about olfactory damage in patients with sleep apnoea syndrome.

\section{Conclusions}

Patients with OSAS appear to suffer from olfactory dysfunction more than adults who are not affected by sleep apnoea syndrome. The degree of olfactory dysfunction appears to be related to severity of disease. However, other factors such as nasal obstruction and reduced mucociliary clearance play a role in of the aetiology of this condition.

\section{References}

1 Pinto JA, Ribeiro DK, Cavallini AF, et al. Comorbidities associated with obstructive sleep apnea: a retrospective study. Int Arch Otorhinolaryngol 2016;20:145-50.

2 Netchitaïlo M, Destors M, Bosc C, et al. Obstructive sleep apnea syndrome. Diagnostic strategies in various clinical settings. Presse Med 2017;46:404-12.

3 Lee SA, Paek JH, Chung YS, et al. Clinical features in patients with positional obstructive sleep apnea according to its subtypes. Sleep Breath 2017;21:109-17.

4 Schwartz RN, Payne RJ, Forest VI, et al. The relationship between upper airway collapse and the severity of obstructive sleep apnea syndrome: a chart review. J Otolaryngol Head Neck Surg 2015;44:32.

5 Buratti L, Luzzi S, Petrelli C, et al. Obstructive sleep apnea syndrome: an emerging risk factor for dementia. CNS Neurol Disord Drug Targets 2016;15:678-82.

6 Hopps E, Caimi G. Obstructive sleep apnea syndrome: links between pathophysiology and cardiovascular complications. Clin Invest Med 2015;38:362-70.

7 Heinzer R, Vat S, Marques-Vidal P, et al. Prevalence of sleep-disordered breathing in the general population: the HypnoLaus study. Lancet Respir Med 2015;3:310-8.

8 Frasnelli J, Hummel T. Olfactory dysfunction and daily life. Eur Arch Otorhinolaryngol 2005;262:231-5.

9 Ciofalo A, Zambetti G, Romeo M, et al. Taste and olfaction in middle ear surgery. Ann Otol Rhinol Laryngol 2015;124:312-6.

10 Frasnelli J, Landis BN, Heilmann S, et al. Clinical presentation of qualitative olfactory dysfunction. Eur Arch Otorhinolaryngol 2004;261:411-5.

11 Hummel T, Kobal G, Gudziol H, et al. Normative data for the "Sniffin' Sticks" including tests of odor identication, odor discrimination, and olfactory thresholds: an upgrade based on a group of more than 3,000 subjects. Eur Arch Otorhinolaryngol 2007;264:237-43.

12 Philpott CM, Boak D. The impact of olfactory disorders in the United Kingdom. Chem Senses 2014;39:711-8.

13 Fonteyn S, Huart C, Deggouj N, et al. Non-sinonasal-related olfactory dysfunction: a cohort of 496 patients. Eur Ann Otorhinolaryngol Head Neck Dis 2014;131:87-91.

14 Nordin S, Brämerson A. Complaints of olfactory disorders: epidemiology, assessment and clinical implications. Curr Opin Allergy ClinImmunol 2008;8:10-5.

15 Deems DA, Doty RL, Settle RG, et al. Smell and taste disorders, a study of 750 patients from the University of Pennsylvania Smell and Taste Center. Arch Otolaryngol Head Neck Surg 1991;117:519-28.

16 Brämerson A, Johansson L, Ek L, et al. Prevalence of olfactory dysfunction: the skövde population-based study. Laryngoscope 2004;114:733-7.

17 Ciofalo A, de Vincentiis M, Zambetti G, et al. Olfactory dysfunction in acute rhinosinusitis: intranasal sodium hyaluronate as adjuvant treatment. Eur Arch Otorhinolaryngol 2017;274:803-8.

18 Frasnelli J, Laguë-Beauvais M, LeBlanc J, et al. Olfactory function in acute traumatic brain injury. Clin Neurol Neurosurg. 2016;140:68-72.

19 Mott AE, Leopold DA. Disorders in taste and smell. Med Clin North Am 1991;75:1321-53.

20 Levrini L, Sacchi F, Milano F. Italian recommendations on dental support in the treatment of adult obstructive sleep apnea syndrome (OSAS). Ann Stomatol 2016;6:81-6.

21 Lachanas VA, Woodard TD, Antisdel JL, et al. Sino-nasal outcome test tool assessment in patients with chronic rhinosinusitis and obstructive sleep apnea. ORL J Otorhinolaryngol Relat Spec 2012;74:286-9.

22 Migueis DP, Thuler LC, Lemes LN, et al. Systematic review: the influence of nasal obstruction on sleep apnea. Braz $\mathrm{J}$ Otorhinolaryngol 2016;82:223-31. 
23 Salihoğlu M, Kendirli MT, Altundağ A, et al. The effect of obstructive sleep apnea on olfactory functions. Laryngoscope 2014;124:2190-4.

24 Günbey E, Güzel A, Karlı R, et al. The relationships between the clinical and polysomnographic findings and the olfactory function in patients with obstructive sleep apnea syndrome. Sleep Breath 2015;19:1301-7.

25 Fu D, Pinto JM, Wang L, et al. The effect of nasal structure on olfactory function in patients with OSA. Eur Arch Otorhinolaryngol 2015;272:357-62.

26 Berry RB, Brooks R, Charlene E., et al. AASM Manual for the Scoring of Sleep and Associated Events. American Academy of Sleep Medicine 2015.

27 Epstein LJ, Kristo D, Strollo PJ Jr, et al. Clinical guideline for the evaluation, management and long-term care of obstructive sleep apnea in adults. J Clin Sleep Med 2009;5:263-76.

28 Hummel C, Zucco GM, Iannilli E, et al. OLAF: standardization of international olfactory tests. Eur Arch Otorhinolaryngol 2012;269:871-80.

29 Hummel T, Sekinger B, Wolf SR, et al. "Sniffin' sticks": olfactory performance assessed by the combined testing of odor identification, odor discrimination and olfactory threshold. Chem Senses 1997;22:39-52.

30 Kobal G, Klimek L, Wolfensberger M, et al. Multicenter investigation of 1,036 subjects using a standardized method for the assessment of olfactory function combining tests of odor identification, odor discrimination, and olfactory thresholds. Eur Arch Otorhinolaryngol 2000;257:205-11.

31 Merkle J, Kohlhas L, Zadoyan G, et al. Rhinomanometric reference intervals for normal total nasal airflow resistance. Rhinology 2014;52:292-9.

32 Ozbay I, Kucur C, Temİzturk F, et al. Assessment of nasal mucociliary activity in patients with Behçet's disease. J Laryngol Otol 2016;130:348-51.

33 Kucur C, Ozbay I, Gulcan E, et al. Evaluation of nasal mucociliary activity in patients with chronic renal failure. Eur Arch Otorhinolaryngol 2016;273:1167-71.

34 Seubert J, Laukka EJ, Rizzuto D, et al. Prevalence and correlates of olfactory dysfunction in old age: a population-based study. J Gerontol A Biol Sci Med Sci 2017;72:1072-9.

35 Migueis DP, Thuler LC, Lemes LN, et al. Systematic review: the influence of nasal obstruction on sleep apnea. Braz $\mathrm{J}$ Otorhinolaryngol 2016;82:223-31.

36 Passali D, Caruso G, Arigliano LC, et al. Database application for patients with obstructive sleep apnoea syndrome. Acta Otorhinolaryngol Ital 2012;32:252-5.

37 Ishii L, Roxbury C, Godoy A, et al. Does nasal surgery improve OSA in patients with nasal obstruction and OSA? A meta-analysis. Otolaryngol Head Neck Surg 2015;153:326-33.
38 Kilicaslan A, Acar GO, Tekin M, et al. Assessment the longterm effects of septoplasty surgery on olfactory function. Acta Otolaryngol 2016;136:1079-84.

39 Toraldo DM, De Nuccio F, De Benedetto M, et al. Obstructive sleep apnoea syndrome: a new paradigm by chronic nocturnal intermittent hypoxia and sleep disruption. Acta Otorhinolaryngol Ital 2015;35:69-74.

40 Passali D, Corallo G, Petti A, et al. A comparative study on oxidative stress role in nasal breathing impairment and obstructive sleep apnoea syndrome. Acta Otorhinolaryngol Ital 2016;36:490-5.

41 Becker S, Pflugbeil C, Gröger M, et al. Olfactory dysfunction in seasonal and perennial allergic rhinitis. Acta Otolaryngol 2012;132:763-8.

42 Berkiten G, Kumral TL, Saltürk Z, et al. Effect of deviated nasal septum type on nasal mucociliary clearance, olfactory function, quality of life, and efficiency of nasal surgery. $\mathrm{J}$ Craniofac Surg 2016;27:1151-5.

43 Bossi R, Piatti G, Roma E, et al. Effects of long-term nasal continuous positive airway pressure therapy on morphology, function, and mucociliary clearance of nasal epithelium in patients with obstructive sleep apnea syndrome. Laryngoscope 2004;114:1431-4.

44 Deniz M, Gultekin E, Ciftci Z, et al. Nasal mucociliary clearance in obstructive sleep apnea syndrome patients. Am J Rhinol Allergy 2014;28:178-80.

45 Basoglu OK, Vardar R, Tasbakan MS, et al. Obstructive sleep apnea syndrome and gastroesophageal reflux disease: the importance of obesity and gender. Sleep Breath 2015;19:585-92.

46 Piumetto E, Sammartano AM, Meinardi G, et al. Diagnostic and therapeutic iter in paediatric OSAS: personal experience. Acta Otorhinolaryngol Ital 2011;31:149-53.

47 Altundag A, Cayonu M, Salihoglu M, et al. Laryngopharyngeal reflux has negative effects on taste and smell functions. Otolaryngol Head Neck Surg 2016;155:117-21.

48 Kabadi A, Saadi M, Schey R, et al. Taste and smell disturbances in patients with gastroparesis and gastroesophageal reflux disease. J Neurogastroenterol Motil 2017;23:370-7.

49 Passàli D, Bellussi L, Bianchini Ciampoli M, et al. Experiences in the determination of nasal mucociliary transport time. Acta Otolaryngol 1984;97:319-23.

50 Carpagnano GE, Spanevello A, Sabato R, et al. Systemic and airway inflammation in sleep apnea and obesity: the role of ICAM-1 and IL-8. Transl Res 2010;155:35-43.

51 McNicholas WT. Obstructive sleep apnea and inflammation. Prog Cardiovasc Dis 2009;51:392-9.

Received: October 26, 2017 - Accepted: January 24, 2018

Address for correspondence: Giuseppe Magliulo, via Gregorio VII 80, 00165 Rome, Italy. Fax +39 0649976817. E-mail: giuseppemagliuloorl@yahoo.com. 